\title{
Proposal to Improve Powertrain Efficiency by Using a Multi-Stage Gearbox
}

\author{
Tomáš Petr
}

\begin{abstract}
This article compares the two types of gearbox designs for an electric car using simulations performed in Ricardo Ignite. The experimental car is being developed at the Technical University of Liberec, and it serves as an open platform for testing and developing new components. The simulation focuses primarily on changing the overall efficiency of the vehicle - its overall range with the new two-stage manual gearbox compared with the current single-stage gearbox. In the simulation, the vehicle will be moving along a horizontal straight trajectory, the speed profile of which is defined by NEDC and WLTP cycles. This article describes the properties of selected types of drivetrain layouts, the existing design and the proposed new concept of the drivetrain layout.
\end{abstract}

Keywords - Electric car, Simulation, MQ200 Gearbox, Efficiency, Ricardo Ignite

\section{INTRODUCTION}

Thanks to high requirements on low emissions, an electric motor drive for passenger cars is becoming a significant competition to conventional combustion engines. For this reason, many manufacturers of passenger cars are gradually placing electric cars in their portfolio. The Technical University of Liberec has seen this trend in the demand for highly qualified experts in this field and is developing a second generation of its own electric car for testing electric drives and batteries.

Internal combustion engines typically reach maximum torque at between 3000 and $5000 \mathrm{rpm}$, so a gearbox is needed to keep the engine in this operating range as the speed of the vehicle increases.

One of the advantages of the electric drive is the fact that the transfer of power does not need a gearbox; this is due to the characteristics of electric motors, which reach a maximum torque from zero speed.

One of the advantages of the electric drive is the fact that the transfer of power does not need a gearbox; this is due to the characteristics of electric motors, which reach a maximum torque from zero speed. That's why most EVs have a single speed.

The efficiency of the electric motor, however, varies; depending on the speed, it varies in the range of 60\%-90\%. For this reason, it is appropriate to ensure that the electric motor is working at optimal speed as often as possible, which can be achieved by adding a multi-stage gearbox.

Tomáš Petr, Student, Department of Vehicles and Engines, Technical University of Liberec, Czech Republic .
The saved-up energy can be used to increase the vehicle's range or to reduce the dimensions of batteries. Another reason for using a multi-stage gearbox are the smaller dimensions of the electric motor, which does not have to be as robust since the gearbox multiplies torque.

\section{EŠUS EXPERIMENTAL VEHICLE}

The eŠus electric experimental car is a four-wheel two-seat Roadster-type vehicle with a rigid frame and front-wheel drive (FWD), see Fig. 1. The frame consists primarily of extruded aluminium profiles. Steel parts are used only on particularly stressed areas of the structure. The used frame design allows easy access to all important parts of the vehicle and allows for easy implementation of the new drive train for test purposes.

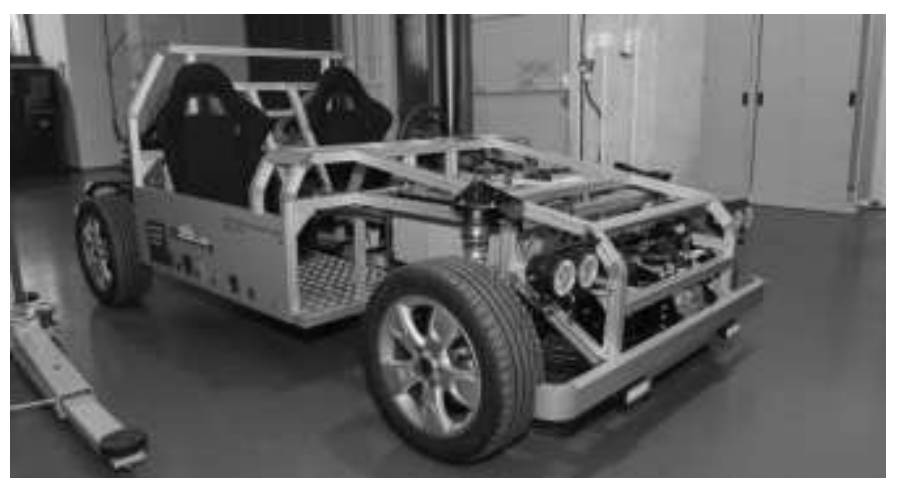

Fig. 1. The eŠus vehicle

\section{A. Vehicle parameters}

The vehicle has a wheelbase of $2462 \mathrm{~mm}$ and a wheel track of $1435 \mathrm{~mm}$. The vehicle's height is $1300 \mathrm{~mm}$ and its length is $3350 \mathrm{~mm}$. The curb weight including the driver is $750 \mathrm{~kg}$. Thanks to the specific use of the two McPherson front axles from Škoda Fabia, it is now possible to develop rear axle control in the vehicle.

The space between the two axles contains a space for the installation of the battery pack with traction battery and BMS. The concept of this vehicle employs as much room as possible for the battery while preserving the comfort of the cabin and luggage compartment. The disadvantage of this concept is the need for a higher placing of the crew due to the minimum height of the battery. The height of the battery ranges from $100 \mathrm{~mm}$ in Tesla Model S/X to $160 \mathrm{~mm}$ in BMW i3. The height of the battery for the eŠus vehicle is $84 \mathrm{~mm}$ [1]. 
TABLE. I: VEHICLE PARAMETERS

\begin{tabular}{|c|c|c|}
\hline \multicolumn{3}{|c|}{ Vehicle parameters } \\
\hline Curb weight & 750 & $\mathrm{~kg}$ \\
\hline Frontal area & 1,8 & $\mathrm{~m}^{2}$ \\
\hline Drag coefficient & 0,4 & \\
\hline Tyre size & $195 / 55 \mathrm{R} 15$ & \\
\hline
\end{tabular}

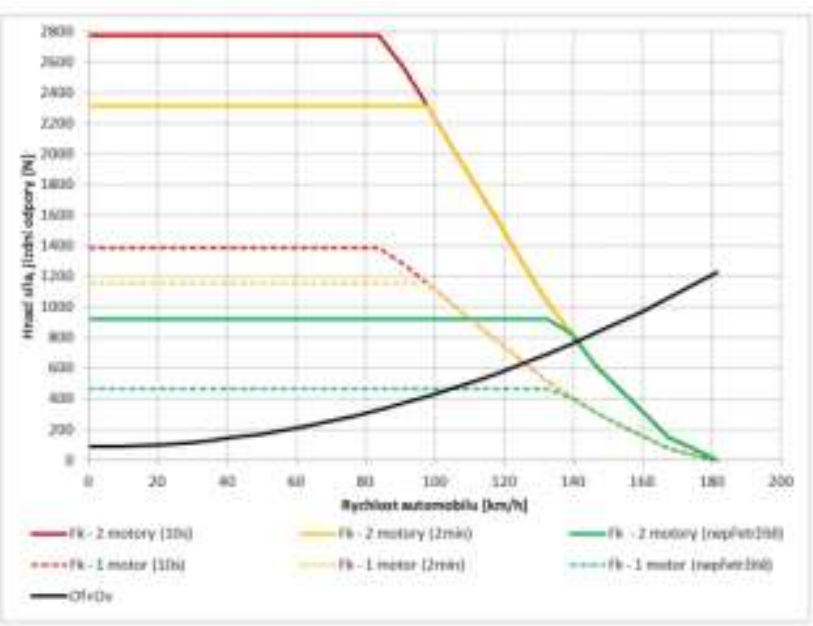

Fig. 2. Driving characteristics of the eŠus vehicle

\section{B. Battery}

The battery modules consist of Saft Vl 41 cylindrical cells of the NCA-C type. The battery cage allows to set the cell modules in two basic versions. The first version allows the installation of 11 battery modules with $18.8 \mathrm{kWh}$ without active thermal management. The second version uses thermal management which allows the installation of 10 modules with $17.2 \mathrm{kWh}$.

This battery will not be considered in the simulation model.

\section{Electric motor}

The electric vehicle is powered with Zero ZF 75-7 electric motors. These are air cooled AC synchronous electric motors with internal permanent magnets with a high efficiency of up to $92 \%$. The electric motor is able to consistently deliver a torque of $45 \mathrm{Nm}$ and power of $17 \mathrm{~kW}$. At its peaks, the motor can deliver up to $31 \mathrm{~kW}$ of power and 86 $\mathrm{Nm}$ of torque. The maximum motor speed is $6000 \mathrm{RPM}$. The electric motor is used with a Sevcon Size 4 controller, thanks to which it can be operated in three different modes: 360 A for 10 seconds, 300 A for 120 seconds and 120 A continuously.

The motor stands out with its low weight of $17 \mathrm{~kg}$ and compact size of $220 \times 250 \times 135 \mathrm{~mm}$.

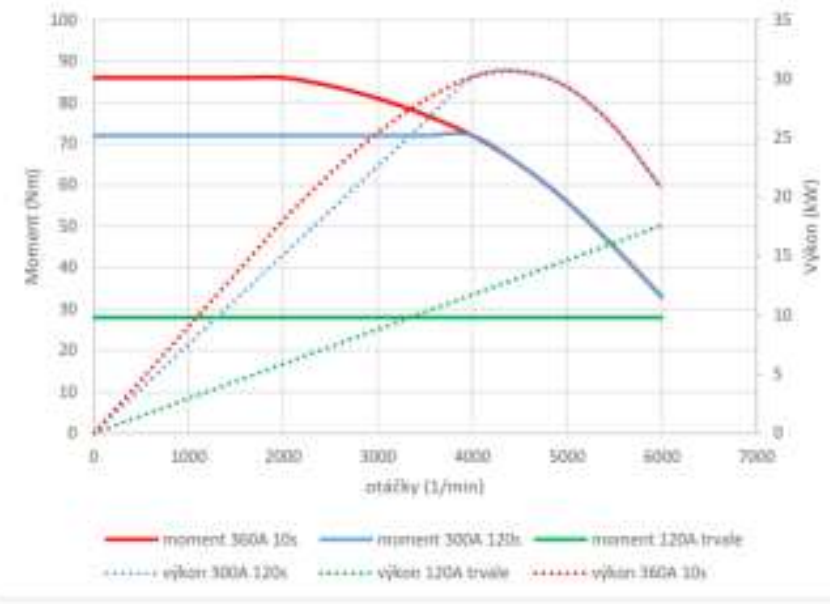

Fig. 3. Torque characteristics of the Zero ZF 75-7 motor

\section{Gearbox}

The two-stage gearbox is based on the design of the MQ200 gearbox by ŠKODA AUTO. It is one of the most commonly used gearboxes in Volkswagen cars. This gearbox is manufactured in 5-stage and 6-stage versions with a maximum torque of $200 \mathrm{Nm}$. The individual gears are engaged via synchronous couplings with sliding sleeves.

This gearbox is used in Škoda Fabia, Škoda Octavia, Škoda Rapid, Volkswagen Golf, Seat Ibiza, and many other cars of the Volkswagen Group in conjunction with positive-ignition and compression-ignition engines.

This gearbox was selected for its parameters, which correspond with the selected Zero ZF 75-7 engine without any complex adjustments.

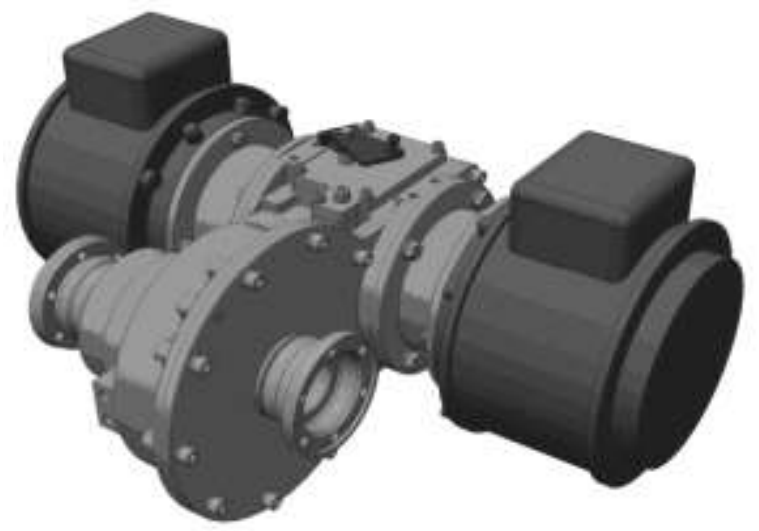

Fig. 4. 3D model of the current gearbox design [1]

\section{CURRENT GeARboX DesigN}

The current concept of the powertrain used in the experimental electric car is referred to as dual motor drive system (DMDS). This concept is used to improve the powertrain parameters using two electric motors attached to a single-stage gearbox, the components of which are taken from the MQ200 02T manual six-stage gearbox, from which the fourth gear with a ratio of 0.881 was selected. Both electric motors currently have the same characteristics. 
The objective is to install two electric motors, each with a different torque characteristic. This arrangement where the two electric motors are installed transversely is advantageous in terms of driving dynamics. If there is no need for high performance and the vehicle moves at a constant speed, only one motor is used, which allows a reduction in the overall energy intensity of the drive. The second motor can only be connected if there is a demand for high performance. Connecting the second electric motor only takes a few milliseconds.

\section{NEW GEARbox DESIGN}

The new design is based on the classic concept of the drivetrain layout. It involves the connection of an electric motor, a two-speed gearbox and a differential.

The advantage of this solution is above all that it keeps the engines in a high efficiency area, increasing the overall efficiency of the EV drive, offering better acceleration and faster speed than existing solutions, and allowing you to use a lower torque engine that is cheaper and reduces the weight of the drive.

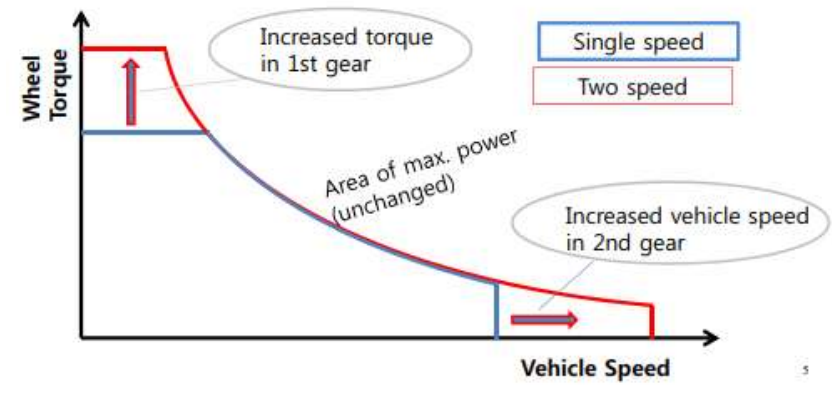

Fig. 5. Comparison of one-stage and two-stage gearboxes [2]

The two-stage gearbox is based on the MQ200 02T manual six-stage gearbox again, from which we will use the splined shafts for the second and fifth gear with a ratio of 1.281 and 0.777 , respectively. The individual gears will be engaged via servomechanisms.

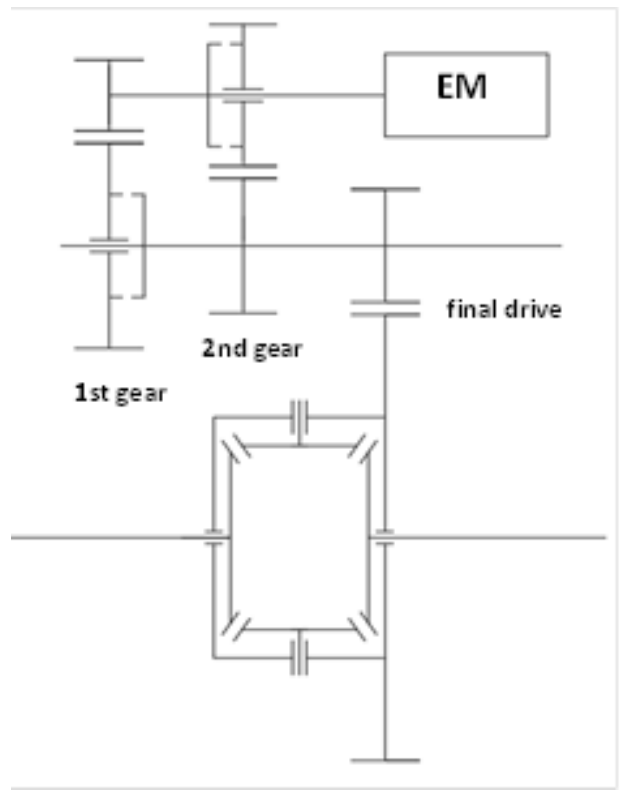

\section{Simulation}

The simulation model was created in Ricardo Ignite. The schematic block diagram of the model is presented in Fig. 7. The mechanical power required for a corresponding reference speed was determined using the torque and the rotation speed of the electric motor. The transmission and battery efficiencies were assumed to be constant throughout the study. The motor and inverter efficiencies were defined by the efficiency maps from the default model. The two-speed gearbox was assumed to have the same efficiency of 0.98 with the single-speed gearbox.

The vehicle's parameters were entered into the software according to the experimental electric car described in the previous chapter.

The simulations were carried out in four driving cycles: NEDC and WLTP Class 3.

\section{A. NEDC cycle}

The NEDC cycle was used in Europe and some other countries up until 2017 as a reference cycle for the approval of vehicles up to EURO6 standards. The cycle starts with four repeats of the UDC cycle, which is an urban cycle created to represent conditions when driving in a city. It is characterized by the low speed of the vehicle, low engine load and low temperature of exhaust gases. The fourth repetition of the UDC cycle is followed by a EUDC cycle, which represents driving outside the city, characterized by greater speed and a more aggressive driving style [3].

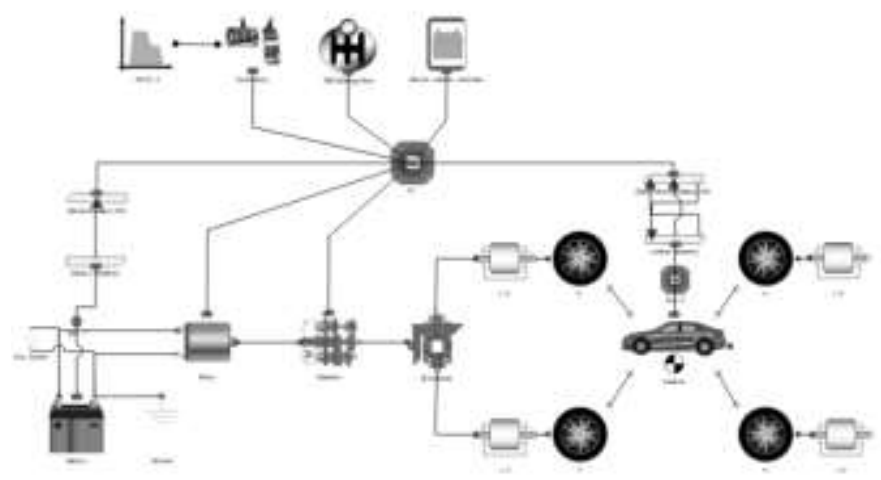

Fig. 6. Simulation model diagram in Ricardo Ignite

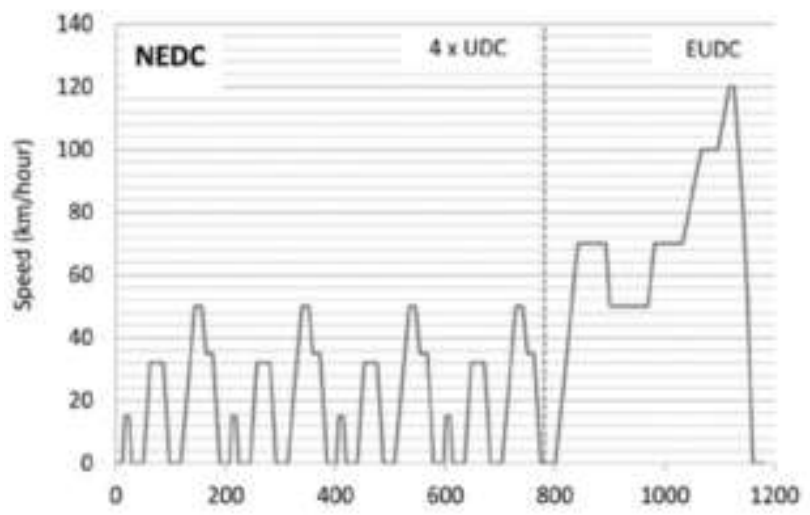

Fig. 7. Speed profile of the NEDC cycle [3] 


\section{B. WLTP cycle}

The WLTP cycle replaces the since obsolete NEDC cycle. WLTP is the collective name for a number of test drive cycles known as WLTC, applicable to different categories of vehicles differentiated by the power-to-weight ratio (PMR) and the maximum speed of the vehicle.

$$
\text { PMR }=\frac{\text { Power }(W)}{\text { Curb weight }(\mathrm{kg})}
$$

The lowest category has a maximum power-to-weight ratio of $22 \mathrm{~kW}$ (29.9 PS) per ton; common-power vehicles have 22 to 34 $\mathrm{kW}$ of power per ton, and high-performance vehicles have a power of over $34 \mathrm{~kW}$ per ton.

This simulation involved a WLTP cycle of the third category, i.e. the category for strong vehicles with a maximum speed over $120 \mathrm{~km} / \mathrm{h}$ (Class 3). Compared to NEDC, the drive is more realistic, dynamic and it corrects all the shortcomings of the previous cycle [4].

In the simulation, the engagement of the individual gears was defined so that when the vehicle accelerated to speeds below 70 $\mathrm{km} / \mathrm{h}$, the first gear was engaged, and when the vehicle drove at a constant speed or a speed greater than $70 \mathrm{kph}$, the second gear was engaged.

The gear-change time was set to 0.5 seconds.

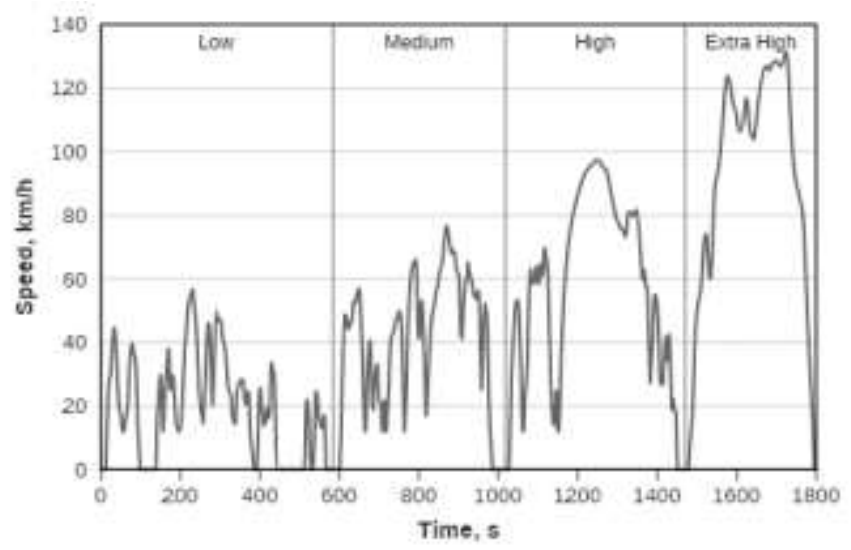

Fig. 8. Speed profile of the WLTP cycle [4]

\section{Simulation Results}

The simulations were conducted on two different cycles: NEDC and WLTP. Figures 11 and 12 show sections of both speed profiles with curves of the required speed, the speed when using the single-stage gearbox, and the speed when using the two-stage gearbox. As shown in the figures, the reactions to the required speeds are adequate and within the prescribed tolerance. For this reason, it is possible to deem the gear ratios appropriate.

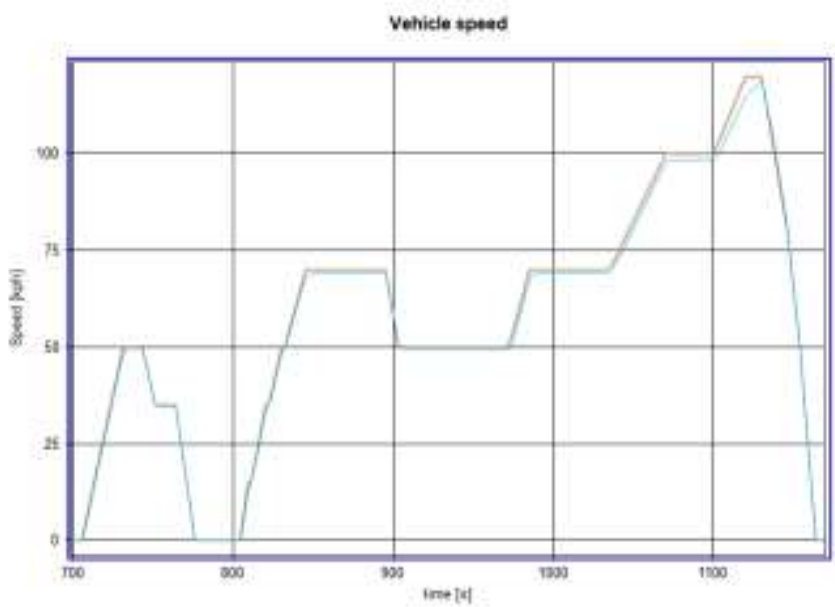

Fig. 9. Section of the NEDC cycle speed profile

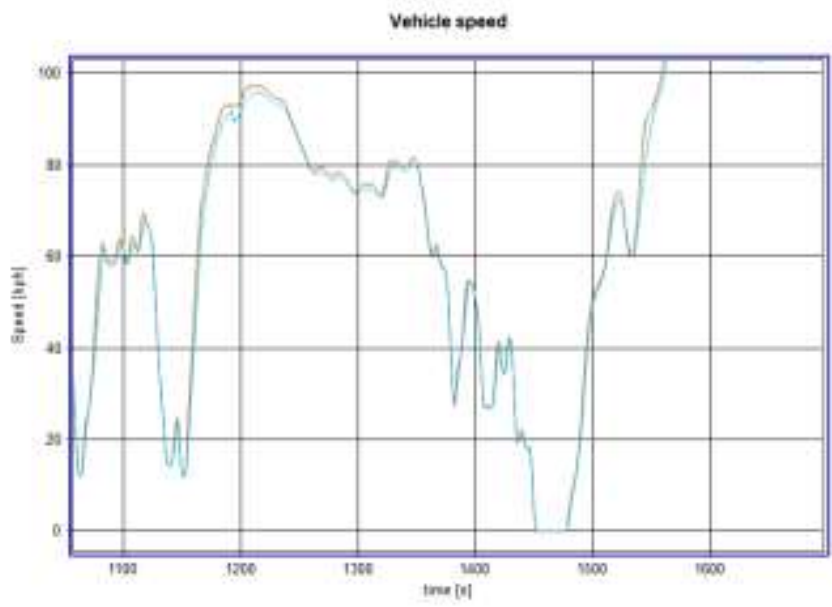

Fig. 10. Section of the WLTP cycle speed profile

The results of the simulation show that when the vehicle was moving at the speed defined by the NEDC, there were no significant deviations between the two examined methods. The SOC graph shows that at the end of the NEDC cycle the battery level was 0.980 with the single-stage gearbox and 0.988 with the two-stage gearbox.

The following graph shows a comparison between the individual examined values on both cycles. The profile of values for the single-stage gearbox is shown in green, and the profile of values for the two-stage gearbox is shown in red. 


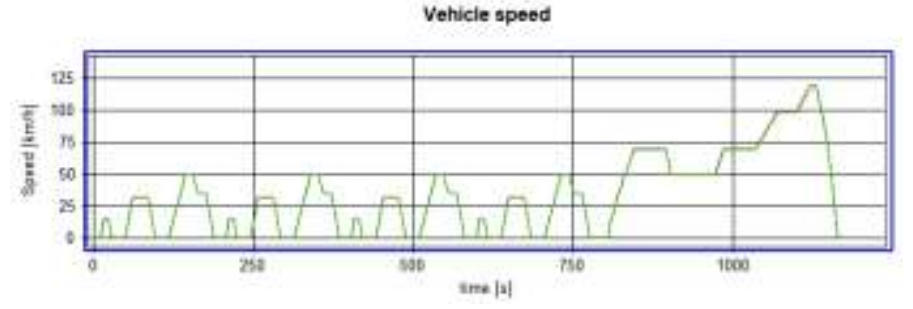

Fig. 9. Vehicle speed (NEDC)

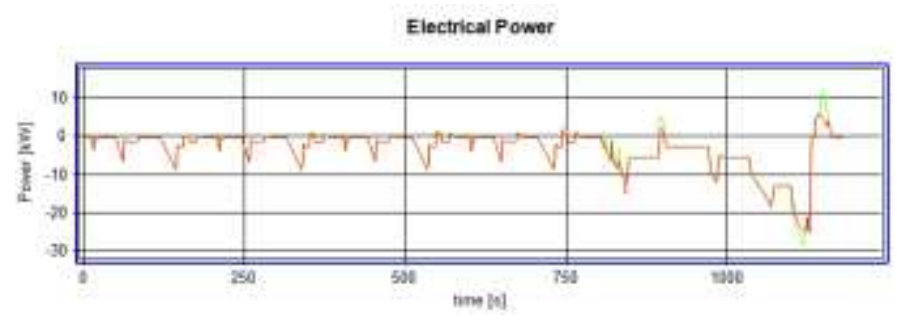

Fig. 12. Electrical Power (NEDC)

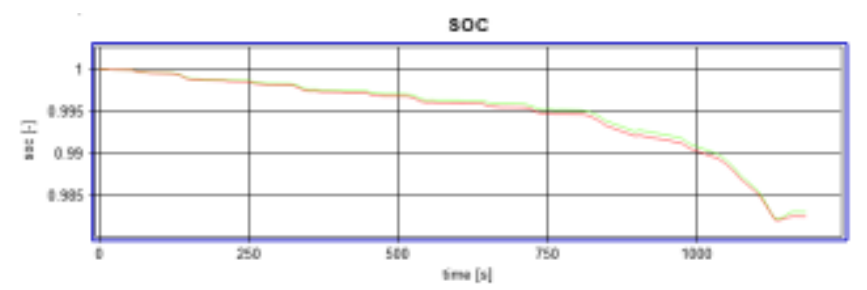

Fig. 13. SOC (NEDC)

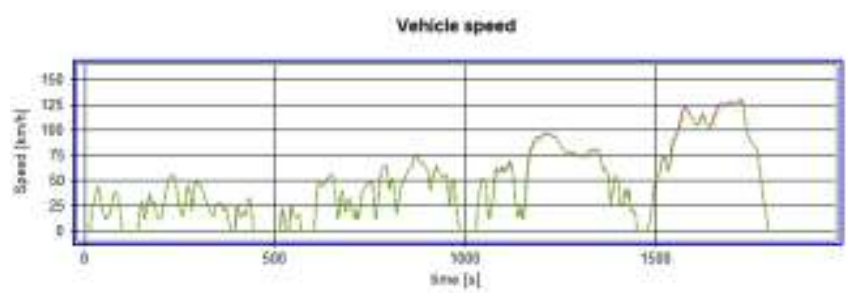

Fig. 14. Vehicle speed (WLTP)

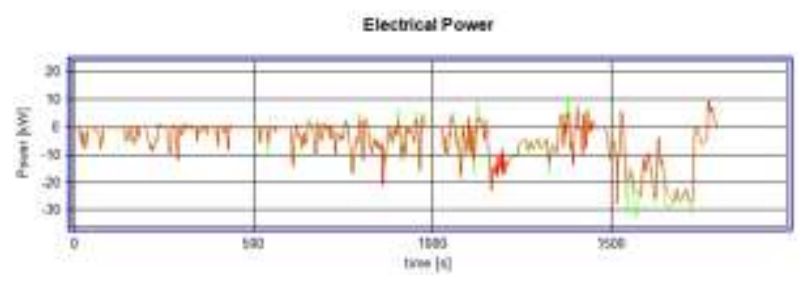

Fig. 15. Electrical Power (WLTP)

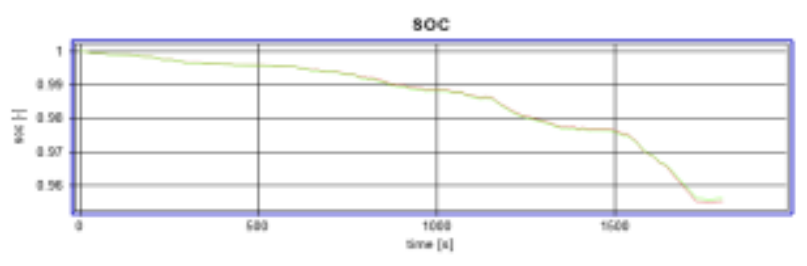

Fig. 16. SOC (WLTP)
In case of the NEDC or the WLTP cycle, the energy savings may seem insignificant. This is due to the length of the NEDC cycle, which is 1180 seconds, or 1800 seconds in case of the WLTP cycle. In the event that the vehicle would endure the cycle for a longer period of time, the energy savings would be more noticeable.

\section{CONCLUSION}

The possibilities for using the two-stage gearbox were only mentioned marginally. The gear ratios for the two-stage gearbox were selected on the basis of a simple optimization. The gear-shifting strategy was selected to use the first gear when driving in the city and the second gear when driving outside the city.

This article has shown the direction for future research on our electric vehicle. One of the topics could involve finding the right combination of motors for use with the two-stage gearbox and improving energy efficiency. Another topic will be to find the correct gear-shifting strategy. This article offers an introduction to this issue. The model created in this research can easily be customized for different applications and for different types of vehicles.

\section{ACKNOWLEDGMENT}

This publication was written at the Technical University of Liberec as part of the project 21127 with the support of the Specific University Research Grant, as provided by the Ministry of Education, Youth and Sports of the Czech Republic in 2018.

\section{REFERENCES}

[1] BŘOUŠEK, Josef, Martin BUKVIC a Pavel JANDURA. EXPERIMENTAL ELECTRIC VEHICLE EŠUS GEN2. Journal of Middle European Construction and Design of Cars. 2016, 6.C.

[2] A Highly Efficient Two Speed Transmission for Electric Vehicles. In: EVS28. Korea, 2015, s. 22.

[3] Emission Test Cycles: ECE 15 + EUDC / NEDC. DieselNet [online]. [cit. 2018-04-28]. https://www.dieselnet.com/standards/cycles/ece_eudc.php

[4] Emission Test Cycles: WLTC. DieselNet [online]. [cit. 2018-04-28].

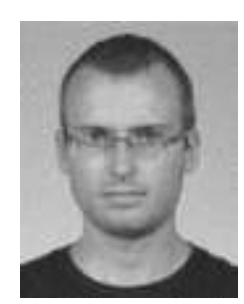

Ing. Tomáš Petr was born in Dvưr Králové nad Labem, Czech Republic, in 1991. He received the B. S. degree (2014) and the M.S. degree (2017) in mechanical engineering from Technical University of Liberec. He is currently pursuing the Ph.D. degree in the field of transport and handling machines at Technical University of Liberec.

From 2016 to 2017, he was an FEA Engineer at LENAM.

His research interests include powertrain design optimization, electric vehicle and vehicle simulations. 